\title{
Efeito de dois sistemas de resfriamento sobre os hormônios tireoidianos e as variáveis termofisiológicas de matrizes suínas em lactação
}

\author{
[Effect of two cooling systems on thyroid hormones and \\ thermophysiological variables of lactating sows] \\ E.J. Rigo $^{1}$, R.C. Antunes ${ }^{2}$, A.V. Mundim ${ }^{2}$, F.C. Gonçalves ${ }^{2}$, \\ E.C. Guimarães ${ }^{3}$, M.R.B. Mattos Nascimento ${ }^{2}$ \\ ${ }^{1}$ Faculdades Associadas de Uberaba - Uberaba, MG \\ ${ }^{2}$ Faculdade de Medicina Veterinária - Universidade Federal de Uberlândia - Uberlândia, MG \\ ${ }^{3}$ Faculdade de Matemática - Universidade Federal de Uberlândia - Uberlândia, MG
}

\begin{abstract}
RESUMO
Avaliaram-se os efeitos do sistema de resfriamento evaporativo com pressão negativa (SRE) e aspersão de água sobre o telhado (AAT), as variáveis termofisiológicas, os hormônios tireoidianos e a relação neutrófilo:linfócito (N:L) em porcas. Utilizaram-se 61 fêmeas em lactação, que foram divididas nos dois ambientes térmicos, sendo $30 \mathrm{em}$ SRE e $31 \mathrm{em} \mathrm{AAT,} \mathrm{no} \mathrm{verão.} \mathrm{A} \mathrm{temperatura} \mathrm{e} \mathrm{a} \mathrm{umidade} \mathrm{do} \mathrm{ar,} \mathrm{a}$ frequência respiratória (FR), as temperaturas de superfície (TS) e retal (TR), a concentração de tiroxina e de tri-iodotironina, o número de neutrófilos e linfócitos e a relação $\mathrm{N}: \mathrm{L}$ foram determinados. A temperatura ambiente pela manhã foi menor em SRE que em AAT $\left(22,1^{\circ} \mathrm{C} v s .23,5^{\circ} \mathrm{C}\right)$ e pela tarde $\left(24,8^{\circ} \mathrm{C}\right.$ vs. $\left.28,0^{\circ} \mathrm{C}\right)$. Em ambos os períodos, a FR, a TS e a TR foram menores em SRE (de manhã 49 resp. $\min ^{-1}, 31,1^{\circ} \mathrm{C}$ e $38,5^{\circ} \mathrm{C}$, respectivamente, e à tarde 55 resp. $\min ^{-1}, 30,3^{\circ} \mathrm{C}$ e $38,8^{\circ} \mathrm{C}$, respectivamente) que em AAT (de manhã 54 resp. $\min ^{-1}, 32,8^{\circ} \mathrm{C}$ e $38,6^{\circ} \mathrm{C}$, respectivamente; e à tarde 65 resp. min $^{-1}, 31,4^{\circ} \mathrm{C}$ e $39,1^{\circ} \mathrm{C}$, respectivamente). Animais sob galpão AAT apresentaram menores concentrações de T4 que animais sob SRE (37,84 vs. 42,22nmol.L $\left.{ }^{-1}\right)$. Em ambiente tropical, no verão, porcas lactantes de ambos os sistemas mantêm a homeotermia.
\end{abstract}

Palavras-chave: suínos, estresse térmico, tireoide, bem-estar

\begin{abstract}
The effects of the evaporative cooling system with negative pressure (ECS) and water spray on the roof (WSR) on physiological variables, thyroid hormones and neutrophil/lymphocyte ratio (N:L) in lactating sows were evaluated. Sixty-one lactating females were divided in the two thermal environments, being 30 in SRE and 31 in the AAT shed in the summer. The air temperature and humidity, respiratory frequency $(R F)$, surface temperatures $(S T)$ and rectal $(R T)$, serum thyroxine and triiodothyronine concentration, number of neutrophils and lymphocytes and the N/L ratio were determined. In the afternoon, the matrices in ECS (Tar: $25.0^{\circ} \mathrm{C}$ and THI: 74.7) and WSR (Tar: $27.6^{\circ} \mathrm{C}$ and THI: 77.3) were exposed to heat stress. In the morning, RF, ST and RT were lower in ECS (49 breaths. $\mathrm{min}^{-1}, 31.1^{\circ} \mathrm{C}$ and $38.5^{\circ} \mathrm{C}$, respectively) than WSR $\left(54\right.$ breaths. min ${ }^{-1}, 32.8^{\circ} \mathrm{C}$ and $\left.38.6^{\circ} \mathrm{C}\right)$ and also in the afternoon ECS (55 breaths.min ${ }^{-1}, 30.3^{\circ} \mathrm{C}$ and $38.8^{\circ} \mathrm{C}$, respectively) and $\mathrm{WSR}\left(65\right.$ breaths. $\mathrm{min}^{-1}, 31.4^{\circ} \mathrm{C}$ and $39.1^{\circ} \mathrm{C}$, respectively). Animals under WSR shed presented lower concentrations of T4 than animals under ECS (37.84 vs 42.22nmol. $\left.L^{-1}\right)$. In a tropical environment, in the summer, lactating sows of both systems maintain homeothermia.
\end{abstract}

Keywords: swine, heat stress, thyroid, welfare

Recebido em 26 de novembro de 2018

Aceito em 29 de abril de 2019

*Autor para correspondência (corresponding author)

E-mail: maran@ufu.br 


\section{INTRODUÇÃO}

Ambientes quentes promovem condições adversas aos suínos e podem prejudicar o seu desempenho e bem-estar. Matrizes suínas em lactação, quando submetidas ao estresse por calor, diminuem o consumo de ração para reduzir a produção de calor metabólico (Renaudeau et al., 2012). A baixa ingestão alimentar provoca redução das reservas corporais, piora a condição corporal, pode desenvolver problemas reprodutivos e menor vida útil das fêmeas (Bloemhof et al., 2008). Matrizes suínas lactantes sob temperatura de $25^{\circ} \mathrm{C}$ reduzem a ingestão alimentar com impacto negativo na massa corporal dos leitões ao desmame (Muns et al., 2016). Alterações no comportamento e na fisiologia (Muns et al., 2016) e redução nos valores dos hormônios tireoidianos (Afsal et al., 2018) também são respostas observadas em porcas sob estresse por calor. A relação neutrófilo/linfócito pode ser um bom marcador quando o estresse por calor é de médio a longo prazo (Quiñonero et al., 2009).

Nesse contexto, as instalações e os equipamentos devem proporcionar proteção e conforto aos suínos. Os sistemas de ventilação forçada com ventiladores ou exaustores, a refrigeração evaporativa (Tolon e Nããs, 2005) e os sistemas de nebulização (Barbari e Conti, 2009) são alternativas que podem promover bons resultados em períodos quentes. Entretanto, os efeitos de diferentes sistemas de refrigeração são escassos, especialmente, estudos com matrizes suínas lactantes em regiões tropicais. Assim, objetivou-se investigar os efeitos do sistema de resfriamento evaporativo com pressão negativa (SRE) e da aspersão de água sobre o telhado (AAT) sobre as variáveis termofisiológicas, os hormônios tireoidianos (T3 e T4) e a relação neutrófilo:linfócito, em matrizes suínas em lactação, no verão, em ambiente tropical.

\section{MATERIAL E MÉTODOS}

O estudo foi aprovado pelo Comitê de Ética e Experimentação Animal da Universidade de Uberaba-Uniube, sob o registro Ceea-068/2016. Este estudo foi elaborado em uma unidade produtora de leitões desmamados (UPD), localizada no distrito de Bom Jesus dos Campos, MG (latitude $20^{\circ} 46^{\prime} 01.4^{\prime \prime} \mathrm{S}$, longitude $46^{\circ} 12^{\prime}$ 26.4"W, e altitude $830 \mathrm{~m}$ ), Brasil, em janeiro de 2017. O estudo foi conduzido em dois galpões, um climatizado com sistema de resfriamento evaporativo com pressão negativa (SRE) e o outro com aspersão de água sobre o telhado (AAT).

O galpão SRE tinha, respectivamente, 111,00; 10,20 e $2,95 \mathrm{~m}$ de comprimento, largura e pé direito, coberto com telha de barro com beiral de $1,10 \mathrm{~m}$, mureta de $0,80 \mathrm{~m}$ de altura, com as laterais de telas metálicas e cortinas e forro de face prata. Essa instalação possuía um sistema de resfriamento evaporativo associado com pressão negativa, com quatro exaustores de 1,30 metros de diâmetro no lado oeste e dois painéis evaporativos com $7,17 \mathrm{~m} \times 1,90 \mathrm{~m}$, instalados no lado leste, nas laterais norte e sul. O sistema de refrigeração evaporativo era ligado e desligado automaticamente quando a temperatura do ar atingia 26 e $24^{\circ} \mathrm{C}$, respectivamente, e era ajustado para manutenção da umidade entre $60 \mathrm{e}$ $80 \%$. O galpão AAT tinha 28,$1 ; 7,77$ e 3,29m, respectivamente, de comprimento, largura e pé direito, cobertos de telha de barro com beiral de $1,0 \mathrm{~m}$, mureta de $0,85 \mathrm{~m}$ de altura, com telas metálicas nas laterais e cortinas plásticas amarelas. $\mathrm{O}$ controle da temperatura era realizado pela abertura e pelo fechamento das cortinas laterais e aspersão de água sobre o telhado durante os horários mais quentes do dia (12h às 14h). As celas parideiras nos dois galpões eram constituídas com piso plástico totalmente ripado, com uma área central para as fêmeas $(0,70 \mathrm{~m}$ de largura $x \quad 2,20 \mathrm{~m}$ de comprimento), e, nas laterais, com duas áreas exclusivas para os leitões $(0,43 \mathrm{~m}$ de largura $\mathrm{x}$ 2,20m de comprimento). Cada gaiola possuía um escamoteador $(0,45 \mathrm{~m}$ de largura $\mathrm{x} 1,00 \mathrm{~m}$ de comprimento) com piso aquecido.

No galpão SRE, utilizaram-se 30 matrizes suínas híbridas, de ordem de parto de um a sete, escolhidas aleatoriamente nas três linhas de gaiolas, na posição próxima ao centro do galpão (Fig. 1). No galpão AAT, alojaram-se 31 matrizes híbridas, com ordem de parto de um a nove, e essas foram distribuídas aleatoriamente em duas linhas de gaiolas (Fig. 2). 


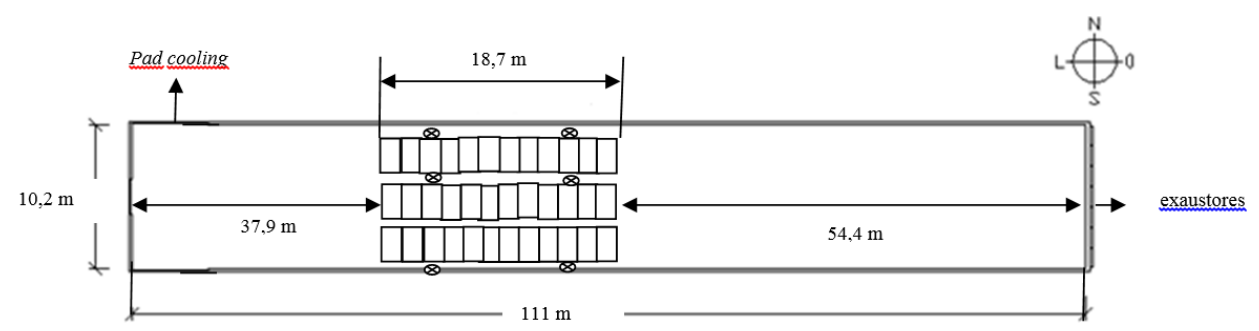

Figura 1. Representação esquemática do galpão maternidade para matrizes suínas com resfriamento evaporativo com pressão negati@ e os dataloggers ( ).

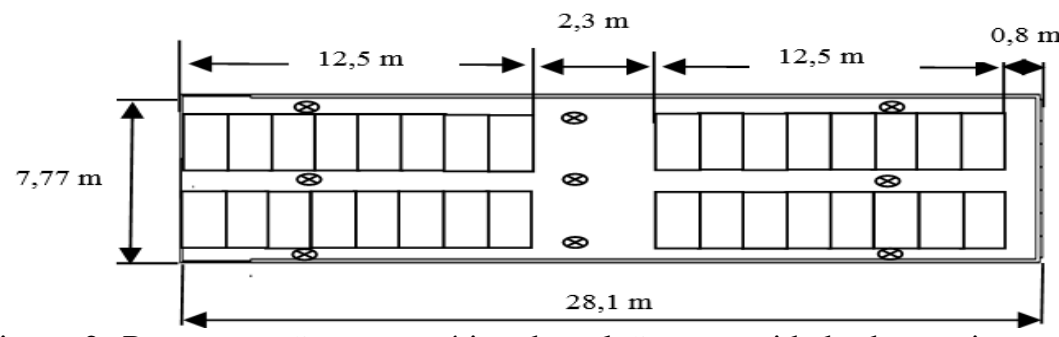

Figura 2. Representação esquemática do galpão maternidade de matrizes suínas com aspersão de água sobre o telhado dos datoggers ( ).

As matrizes receberam diariamente ração de lactação à base de milho e farelo de soja, com $19,6 \%$ de proteína bruta e $3.469,73 \mathrm{kcal}$ de $\mathrm{EM} / \mathrm{kg}$. No dia do parto, a ração não foi oferecida e, em seguida, do segundo até o sétimo dia de lactação, a quantidade foi crescente; quando se estabilizou, cada matriz recebia, em média, $0,573 \mathrm{~kg} /$ leitão. A ração foi fracionada e fornecida automaticamente às sete, 10,12 e 15 horas. Diariamente, antes da primeira refeição, pesou-se a sobra de ração para o cálculo do consumo médio diário. As matrizes e os leitões receberam água à vontade, em bebedouro tipo nipple.

As variáveis fisiológicas foram medidas de manhã e à tarde, em cinco dias não consecutivos, iniciando um dia antes do parto previsto até o desmame dos leitões. A frequência respiratória foi medida com as matrizes em repouso, sem estarem amamentando, em decúbito, pela avaliação dos movimentos do flanco por um minuto. A temperatura superficial foi medida atrás da orelha, no meio da escápula, na região mediana do dorso e no meio do pernil, com termômetro infravermelho com emissividade de 0,95 (Instrutemp, modelo DT 8530), com variação de $-20^{\circ} \mathrm{C}$ a $530^{\circ} \mathrm{C}$, e calculou-se a média. Depois de 40 a 60 minutos após a alimentação, mediu-se a temperatura retal com termômetro clínico digital (Tech Line, modelo
TS-101), faixa de $32^{\circ} \mathrm{C}$ a $42,9^{\circ} \mathrm{C}$, a cinco centímetros de profundidade.

Cinco mililitros (mL) de sangue foram puncionados da veia jugular externa de cada animal, no sétimo dia após o parto, de manhã (oito - 10 horas), e colocados em tubos sem e com anticoagulante (EDTA). Nas amostras de sangue com EDTA, realizaram-se os esfregaços, que foram marcados usando-se o método panótico rápido por Romanovsky, conforme Stokol e Erb (2007); o número de neutrófilos e linfócitos foram obtidos a partir da contagem em aparelho ABX Micros 60, e calculou-se a relação neutrófilos:linfócitos (N/L). O sangue sem anticoagulante foi centrifugado por cinco minutos, armazenado em microtubos numerados Eppendorf), que foram mantidos na temperatura de $-20^{\circ} \mathrm{C}$ até análise dos hormônios tireoidianos. As concentrações séricas de T3 e T4 foram realizadas pelo teste de enzimaimunoensaio (ELISA). Foi utilizado o kit da interkit (Bio check, Inc.), em analisador automático multicanal Chemwell ${ }^{\circledR}$, no Laboratório de Patologia Clínica do Hospital Veterinário da Universidade Federal de Uberlândia, conforme Storti et al. (2012).

A temperatura, a umidade do ar e a temperatura de ponto de orvalho foram registradas por dataloggers (Instrutherm, modelo HT-500), instalados próximo das matrizes, a cada 30 
minutos, nos cinco dias das coletas das variáveis fisiológicas, durante o dia. A velocidade do vento foi medida com anemômetro (Instruterm AD-250) colocado na altura das matrizes.

Do lado de fora do galpão, foi colocado um datalogger dentro de um abrigo, com a finalidade de avaliar a amortização das condições meteorológicas pelos sistemas de resfriamento. Calculou-se o índice de temperatura e umidade (ITU), conforme Thom (1959).

Para a análise dos dados, foi feito o teste de normalidade e homocedasticidade e verificou-se que a maioria das variáveis apresentou distribuição não normal ou variância heterocedástica, portanto optou-se por teste não paramétrico (Campos, 1984). Foi utilizado o teste de Mann-Whitney, para avaliar duas amostras, e o teste de Kruskal-Wallis, para três amostras. Adotou-se o nível de significância de $5 \%$, e os procedimentos foram realizados no programa computacional IBM SPSS 20 (2011).

\section{RESULTADOS E DISCUSSÃO}

A temperatura do ar e o ITU aumentaram de manhã para tarde nos três ambientes (Tab. 1). Isso pode ter ocorrido devido ao fato de o ambiente matutino ter menor influência do aquecimento solar, o qual é cumulativo durante o dia. A Tar e o ITU, de manhã, no SRE, não diferiram do meio externo e foram menores que no galpão AAT; à tarde, foram menores que no AAT e no meio externo (Tab. 1). Apesar disso, todas as temperaturas foram acima da termoneutralidade para as matrizes suínas lactantes, conforme Willians et al. (2013), que recomendaram valores de 18 a $20^{\circ} \mathrm{C}$. Os valores de ITU, durante a manhã, estiveram dentro da zona termoneutra para matrizes suínas em lactação, conforme Wegner et al. (2016), que consideraram valores de ITU $\leq 74$ sem estresse por calor. À tarde, o ITU em SRE foi próximo a 74, que constitui condição de conforto térmico; já no galpão AAT e externo, foram acima do ideal para matrizes suínas, representando, portanto, uma situação de estresse por calor. Justino et al. (2015) verificaram que, nos sistemas de resfriamento da nuca e no sistema de cortinas, o ITU esteve dentro do conforto térmico de manhã (71 e 73,8, respectivamente) e à tarde apresentou, respectivamente, situação de alerta $(77,2)$ e perigo $(80,6)$ para matrizes suínas lactantes.

De manhã a UR foi maior que à tarde em todos os ambientes (Tab. 1). Esse resultado era esperado, uma vez que seu comportamento é oposto à Ta. De manhã e à tarde, a UR foi maior em SRE que em ATT e externo, contudo os últimos não diferiram entre si (Tab. 1). Esse resultado também era esperado, uma vez que, no sistema pad cooling, o resfriamento é realizado por vapor de água. Sob ambiente quente, a umidade do ar é um importante fator a ser considerado. Entretanto, no galpão SRE, quando a temperatura alcançava $26^{\circ} \mathrm{C}$ (limite dentro do desejável para matrizes suínas de acordo com Myer e Bucklin, 2018), o sistema ligava, com a finalidade de reduzir a temperatura do ar e favorecer a transferência de calor sensível (condução, convecção e radiação).

Tabela 1. Mediana (md), média, máximo e mínimo da temperatura do ar (Ta), umidade relativa (UR) e índice de temperatura e umidade (ITU) de manhã (M) e à tarde (T), em galpões de maternidade de suínos, com resfriamento evaporativo com pressão negativa (SRE), aspersão de água sobre o telhado (AAT) e fora dos galpões (externo)

\begin{tabular}{|c|c|c|c|c|c|c|c|c|c|c|c|c|c|}
\hline & & \multicolumn{4}{|l|}{ SRE } & \multicolumn{4}{|l|}{ AAT } & \multicolumn{4}{|l|}{ Externo } \\
\hline & & $\mathrm{md}$ & Média & Máx & Mín & $\mathrm{md}$ & Média & Máx & Mín & md & Média & máx & Mín \\
\hline \multirow{2}{*}{$\mathrm{Ta}^{\circ} \mathrm{C}$} & M & $22,2 \mathrm{Aa}$ & 22,1 & 23,3 & 21,1 & $24,1 \mathrm{Ab}$ & 23,5 & 25,5 & 22,9 & $23,5 \mathrm{Aab}$ & 24,2 & 25,4 & 22,2 \\
\hline & $\mathrm{T}$ & $25,0 \mathrm{Ba}$ & 24,8 & 26,3 & 23,1 & 27,6 & 28,0 & 34,6 & 25,3 & & 30,0 & 31,2 & 27,3 \\
\hline \multirow{2}{*}{ UR\% } & M & $95,2 \mathrm{Aa}$ & 95,2 & 98,2 & 92,5 & 87, & 88,3 & 95,6 & 80,5 & & 87,0 & 90,1 & 83,7 \\
\hline & $\mathrm{T}$ & 91,5 & 90,1 & 96,2 & 83,4 & 76 & 76,3 & 89,0 & 61,2 & 62 & 64 & 73,0 & 60,1 \\
\hline \multirow{2}{*}{ ITU } & $\mathrm{M}$ & 71,3Aa & 71,3 & 72,9 & 69,9 & $73,6 \mathrm{Ab}$ & 73,7 & 75,8 & 71,7 & $72,3 \mathrm{Aab}$ & 72,5 & 74,8 & 71,1 \\
\hline & $\mathrm{T}$ & $74,7 \mathrm{Ba}$ & 74,6 & 76,7 & 72,6 & $77,3 \mathrm{Bb}$ & 77,9 & 85,1 & 75,0 & $80,6 \mathrm{Bb}$ & 79,4 & 81,0 & 76,6 \\
\hline
\end{tabular}

Dentro de cada variável, medianas, seguidas por letras iguais maiúsculas (COLUNA) pelo teste de Mann-Whitney e minúsculas (LINHA) pelo teste de Kruskal-Wallis, não diferem entre si a 5\%.

Morales et al. (2013), ao avaliarem matrizes suínas na maternidade com resfriamento evaporativo-SRE, resfriamento da nuca-RN e manejo de cortinas-MC, obtiveram Tar menores no SRE que em RN e MC de manhã, elevando-se à tarde nos três sistemas. As umidades relativas 
foram maiores de manhã nos três sistemas em relação à tarde, apresentando um comportamento inverso entre a umidade e a temperatura do ar.

A frequência respiratória foi menor de manhã em comparação ao período da tarde nos animais dos dois sistemas de resfriamento (Tab. 2). Esse resultado pode ser explicado, em parte, pela maior temperatura ambiente à tarde que, consequentemente, exigiu maior dissipação de calor para o ambiente por evaporação, elevando a frequência respiratória. As médias de frequência respiratória dos animais em AAT foram superiores à das SRE, tanto de manhã quanto à tarde. Quando a temperatura ambiente estava acima da temperatura crítica superior para matrizes em lactação, ou seja, maior que $20^{\circ} \mathrm{C}$ (Willians et al., 2013), as porcas aumentaram os movimentos respiratórios, num esforço de elevar a perda por evaporação, pois a diferença entre as temperaturas do ar e do corpo foi pequena, prejudicando a dissipação não-evaporativa. Justino et al. (2015) observaram valores de frequência respiratória de manhã, em porcas no SRE, de 37,92 resp. $\mathrm{m}^{-1}$ e, no sistema de ventilação natural (SVN), de 46,25 resp. ${ }^{-1}$, valores inferiores aos verificados no presente estudo durante a manhã. No período da tarde, os valores observados por Justino et al. (2015) foram de 56,42 e 80,09 resp. m $^{-1}$, para SRE e $\mathrm{SVN}$, respectivamente (valores maiores que os registrados no presente estudo à tarde). Por outro lado, ao considerar que a frequência respiratória é um dos mecanismos fisiológicos utilizados pelos suínos para aumentar a perda de calor para o meio ambiente num ambiente quente e que foi maior nos animais sob AAT que SRE, tanto de manhã quanto à tarde, pode-se dizer que os animais em galpão com AAT foram submetidos a maior desconforto térmico.

A temperatura da orelha, da paleta, do lombo e do pernil das matrizes aumentou do período da manhã para o da tarde e foi maior em porcas em AAT que em SRE (Tab. 2). Esse resultado era esperado, uma vez que, sob estresse por calor, observa-se maior fluxo sanguíneo do interior do corpo para a periferia associado com vasodilatação periférica para aumentar a dissipação de calor. O aumento da FR e de TS são estratégias para lidar com a alta temperatura ambiente, por meio da evaporação pelos pulmões e por aumento do fluxo sanguíneo para a pele, respectivamente (Muns et al., 2016).

Tabela 2. Mediana, média, desvio-padrão da frequência respiratória (FR), temperatura superficial média (TSM), temperaturas da orelha, da paleta, do lombo e do pernil e temperatura retal de matrizes suínas lactantes de manhã e à tarde, alojadas em galpão com sistema de resfriamento evaporativo (SRE) ou com aspersão de água no telhado (AAT)

\begin{tabular}{llllll}
\hline & & SRE & & AAT & \\
\hline Variável & Período & Mediana & Média \pm DP & Mediana & Média \pm DP \\
\hline \multirow{2}{*}{ FR (respirações/minuto) } & Manhã & $48,0 \mathrm{Aa}$ & $49 \pm 17,0$ & $52,0 \mathrm{Ab}$ & $54 \pm 18,0$ \\
& Tarde & $54,0 \mathrm{Ba}$ & $55 \pm 19,0$ & $64,0 \mathrm{Bb}$ & $65 \pm 23,0$ \\
TSM $\left({ }^{\circ} \mathrm{C}\right)$ & Manhã & $31,2 \mathrm{Aa}$ & $31,1 \pm 1,2$ & $32,9 \mathrm{Ab}$ & $32,8 \pm 1,0$ \\
& Tarde & $32,5 \mathrm{Ba}$ & $32,5 \pm 1,1$ & $34,3 \mathrm{Bb}$ & $34,4 \pm 1,2$ \\
T orelha $\left({ }^{\circ} \mathrm{C}\right)$ & Manhã & $30,4 \mathrm{Aa}$ & $30,3 \pm 1,9$ & $31,4 \mathrm{Ab}$ & $31,4 \pm 1,7$ \\
& Tarde & $31,5 \mathrm{Ba}$ & $31,3 \pm 1,8$ & $32,9 \mathrm{Bb}$ & $33,0 \pm 2,0$ \\
T paleta $\left({ }^{\circ} \mathrm{C}\right)$ & Manhã & $31,3 \mathrm{Aa}$ & $30,8 \pm 1,9$ & $32,6 \mathrm{Ab}$ & $32,4 \pm 1,6$ \\
\multirow{2}{*}{ T lombo $\left({ }^{\circ} \mathrm{C}\right)$} & Tarde & $32,6 \mathrm{Ba}$ & $32,3 \pm 1,5$ & $34,3 \mathrm{Bb}$ & $34,2 \pm 1,6$ \\
& Manhã & $31,6 \mathrm{Aa}$ & $31,3 \pm 1,4$ & $33,5 \mathrm{Ab}$ & $33,3 \pm 1,4$ \\
T pernil $\left({ }^{\circ} \mathrm{C}\right)$ & Tarde & $32,8 \mathrm{Ba}$ & $32,4 \pm 1,7$ & $34,9 \mathrm{Bb}$ & $34,6 \pm 1,6$ \\
& Manhã & $32,1 \mathrm{Aa}$ & $32,0 \pm 1,3$ & $34,2 \mathrm{Ab}$ & $34,0 \pm 1,1$ \\
Temperatura retal $\left({ }^{\circ} \mathrm{C}\right)$ & Tarde & $34,0 \mathrm{Ba}$ & $33,8 \pm 1,2$ & $36,0 \mathrm{Bb}$ & $35,8 \pm 1,0$ \\
& Manhã & $38,5 \mathrm{Aa}$ & $38,5 \pm 0,5$ & $38,6 \mathrm{Ab}$ & $38,6 \pm 0,5$ \\
& Tarde & $38,8 \mathrm{Ba}$ & $38,8 \pm 0,6$ & $39,1 \mathrm{Bb}$ & $39,1 \pm 0,6$ \\
\hline
\end{tabular}

Medianas seguidas por letras iguais maiúsculas (COLUNA) e minúsculas (LINHA) não diferem entre si pelo teste de MannWhitney a $5 \%$.

A temperatura retal das porcas também foi menor de manhã em relação ao período da tarde, independentemente do tipo do galpão. Esse resultado pode ser explicado tanto pela maior temperatura ambiente à tarde como pelo ritmo circadiano (variação nas 24 horas). Porcas sob AAT apresentaram maior temperatura retal que as alojadas em SRE (Tab. 2), porém estiveram dentro do padrão fisiológico, que é de 38 a 39, $3^{\circ} \mathrm{C}$ (Quiniou e Noblet, 1999). Apesar da 
manutenção da homeotermia, animais em galpão AAT apresentaram maior dissipação de calor por evaporação (maior frequência respiratória) que porcas sob SRE. Também houve acréscimo da temperatura superficial sob AAT, possivelmente por causa do maior fluxo sanguíneo periférico na tentativa de aumentar a dissipação de calor.

Além de afetar as respostas termorregulatórias, acredita-se que o estresse por calor modifique os perfis hormonais em animais homeotérmicos (Campos et al., 2014). Esses autores observaram que a exposição ao estresse por calor resultou em uma diminuição dos hormônios T3 e T4, seguida por um aumento gradual ao longo do tempo. Afirmaram que esse resultado sugere que os hormônios da tireoide também estão envolvidos na aclimatação dos suínos, a uma carga de calor sustentada por um efeito direto ou indireto na taxa metabólica. Entretanto, afirmaram que ainda não está claro se o declínio de T3 e T4 em relação à duração da exposição a $30^{\circ} \mathrm{C}$ ocorre em resposta direta à inibição térmica do hipotálamo ou como efeito indireto de menor consumo de ração e metabolismo.

Afsal et al. (2018) relataram que o eixo hipotálamo-hipófise-tireoide desempenha um papel importante na regulação do gasto energético, afetando a taxa metabólica basal por meio das ações dos hormônios tireoidianos. Esses autores afirmaram ainda que, nos animais de interesse zootécnico submetidos ao estresse por calor por longo período, observa-se uma diminuição da atividade do eixo hipotálamohipófise-tireoide com a finalidade de reduzir a produção de calor metabólico. Prunier et al. (1997) verificaram menores concentrações de T3 e de T4 em fêmeas suínas criadas sob $30^{\circ} \mathrm{C}$ em relação àquelas alojadas num ambiente de $20^{\circ} \mathrm{C} \mathrm{e}$ afirmaram que provavelmente esse resultado está relacionado ao efeito termogênico desses hormônios e que pode ser considerado como um mecanismo adaptativo para reduzir a produção de calor. No presente estudo, as concentrações de T3 e T4 livre não diferiram entre as porcas criadas sob SRE e aquelas mantidas sob AAT (Tab. 3). Porém, animais sob AAT apresentaram menores concentrações séricas de T4 que animais sob SRE (Tab. 3). Essa redução, provavelmente foi um mecanismo para reduzir a produção de calor e auxiliar no controle da homeotermia, uma vez que as matrizes suínas no galpão AAT estiveram sob pior ambiente térmico.

Tabela 3. Mediana, média e desvio-padrão do número e porcentagem de neutrófilos e linfócitos, da relação neutrófilo:linfócito (N/L) e da concentração sérica dos hormônios tireoidianos de matrizes suínas em lactação alojadas em galpão com sistema de resfriamento evaporativo por pressão negativa (SRE) ou com aspersão de água no telhado (AAT)

\begin{tabular}{llll}
\hline Variáveis & & Mediana & Média \pm DP \\
\hline T3 $\left(\mathrm{nmol} . \mathrm{L}^{-1}\right)$ & SRE & $0,0151 \mathrm{a}$ & $0,0174 \pm 0,401$ \\
& AAT & $0,0144 \mathrm{a}$ & $0,0159 \pm 0,343$ \\
T4 $\left(\mathrm{nmol} . \mathrm{L}^{-1}\right)$ & SRE & $42,22 \mathrm{a}$ & $42,174 \pm 4,325$ \\
& AAT & $37,84 \mathrm{~b}$ & $37,640 \pm 4,286$ \\
T4 livre $\left(\mathrm{pmol} . \mathrm{L}^{-1}\right)$ & SRE & $9,459 \mathrm{a}$ & $10,219 \pm 2,819$ \\
& AAT & $9,910 \mathrm{a}$ & $10,412 \pm 1,892$ \\
Neutrófilos $(/ \mu \mathrm{L})$ & SRE & $12586,50 \mathrm{a}$ & $13628,86 \pm 3831,20$ \\
& AAT & $10850,00 \mathrm{a}$ & $11898,19 \pm 4016,41$ \\
Neutrófilos $(\%)$ & SRE & $77,00 \mathrm{a}$ & $74,54 \pm 10,665$ \\
& AAT & $80,00 \mathrm{a}$ & $78,19 \pm 9,300$ \\
Linfócitos $(/ \mu \mathrm{L})$ & SRE & $3295,50 \mathrm{a}$ & $3766,14 \pm 1719,18$ \\
& AAT & $2560,00 \mathrm{~b}$ & $2689,52 \pm 1007,25$ \\
Linfócitos $(\%)$ & SRE & $19,00 \mathrm{a}$ & $20,79 \pm 8,474$ \\
& AAT & $17,00 \mathrm{a}$ & $18,87 \pm 8,686$ \\
Relação N/L & SRE & $4,001 \mathrm{a}$ & $4,544 \pm 2,780$ \\
& AAT & $4,765 \mathrm{a}$ & $5,101 \pm 2,379$ \\
\hline
\end{tabular}

Medianas, seguidas por letras iguais minúsculas na coluna, dentro de cada parâmetro, não diferem entre si pelo teste de MannWhitney a $5 \%$. DP = desvio-padrão.

A razão entre neutrófilos e linfócitos (N/L) e as concentrações de corticoides em porcas gestantes foram consideradas marcadores fisiológicos de estresse por Quiñonero et al. (2009). Concluíram que, quando os animais são submetidos ao estresse por calor por um período de médio a 
longo prazo, a relação N/L é um bom indicador e que a concentração de corticoides mostrou maior variabilidade e foi um marcador de estresse mais eficiente quando os animais foram submetidos ao estresse por curto prazo. Hyun et al. (2005) encontraram menor concentração de linfócitos e maior de neutrófilo e consequentemente maior relação N/L em suínos em crescimento ao final de quatro semanas sob estresse cíclico de calor $\left(28^{\circ} \mathrm{C}\right.$ a $\left.34^{\circ} \mathrm{C}\right)$. Assim, é esperado que a relação $\mathrm{N} / \mathrm{L}$ aumente em situações de estresse por calor, entretanto, no presente estudo, o número de neutrófilos, a relação N/L e a porcentagem de neutrófilos e de linfócitos não diferiram entre matrizes sob SRE e em galpão AAT, apesar da maior temperatura do ar e de maior ITU no sistema AAT em comparação ao SRE, porém o número de linfócitos foi menor em animais sob galpão AAT que SRE (Tab. 3).

Por fim, é necessário prover um bom sistema de resfriamento para as matrizes lactantes, por exemplo, o SRE. Entretanto, é importante lembrar que as porcas e os leitões têm exigências térmicas diferentes, sendo a matriz sensível a elevadas temperaturas e o leitão sensível ao frio. Assim, é vital fornecer um ambiente ótimo para os leitões, como o uso do escamoteador, aquecimento e luminosidade.

\section{CONCLUSÕES}

Porcas lactantes criadas em galpão com sistema de resfriamento evaporativo por pressão negativa apresentam frequência respiratória, tiroxina, temperaturas superficial e retal inferiores aos de porcas mantidas sob resfriamento por aspersão de água sobre o telhado, no verão, em ambiente tropical, porém os animais de ambos os sistemas mantêm a homeotermia.

\section{AGRADECIMENTOS}

"O presente trabalho foi realizado com apoio da Coordenação de Aperfeiçoamento de Pessoal de Nível Superior - Brasil (CAPES) - Código de Financiamento 001".

\section{REFERÊNCIAS}

AFSAL, A.; SEJIAN, V.; BAGATH, M. et al. Heat stress and livestock adaptation: neuroendocrine regulation. Int. J. Vet. Anim. Med., v.1.2, p.1-8, 2018. Disponível em: $<$ https://www.boffinaccess.com/open-accessjournals/international-journal-of-veterinary-andanimal-medicine/ijvam-1-108.pdf $>$. Acessado em: 03 out. 2018.

BARBARI, M.; CONTI, L. Use of different cooling systems by pregnant sows in experimental pen. Biosyst. Eng., v.103, p.239244, 2009.

BLOEMHOF, S.; VAN DER WAAIJ, E.H.; MERKS, J.W.M. et al. Sow line differences in heat stress tolerance expressed in reproductive performance traits. J. Anim. Sci., v.86, p.33303337, 2008.

CAMPOS, H. Estatística experimental nãoparamétrica. Piracicaba: Departamento de Matemática e Estatística, 1984. 332p.

CAMPOS, P.H.R.F.; NOBLET, J.; AGUELINPEYRAUD, Y. et al. Thermoregulatory responses during thermal acclimation in pigs divergently selected for residual feed intake. Int. J. Biometeorol., v.58, p.1545-1557, 2014.

HYUN, Y.; ELLIS, M.; S.E. CURTIS, E.S. et al. Environmental temperature, space allowance, and regrouping: additive effects of multiple concurrent stressors in growing pigs. J. Swine Health Prod., v.13, p.131-138, 2005.

IBM SPSS Statistics for Windows. Version 20.0. Armonk, NY: IBM Corp, 2011.

JUSTINO, E.; NÄÄS, I.A.; CARVALHO, T.M.R. et al. Efeito do resfriamento evaporativo e do balanço eletrolítico sobre a lactação de porcas em condições de verão tropical. Arq. Bras. Med. Vet. Zootec., v.67, p.455-464, 2015.

MORALES, O.E.S.; GONÇALVES, M.A.D.; STORTI, A.A. et al. Effect of different systems for the control of environmental temperature on the performance of sows and their litters. Acta Sci. Vet., v.41, p.1-7, 2013. Disponível em: <http://www.ufrgs.br/actavet/41/PUB\%201111.p df>. Acessado em: 21 maio 2018. 
MUNS, R.; MALMKVIST, J.; LARSEN, M.L.V. et al. High environmental temperature around farrowing induced heat stress in crated sows. J. Anim. Sci., v.94, p.377-384, 2016.

MYER, R.; BUCKLIN, R. Influence of hothumid environment on growth performance and reproduction of swine. 2018. Disponível em: $<$ https://edis.ifas.ufl.edu/pdffiles/AN/AN10700.p df > . Acessado em: 12 abr. 2019.

PRUNIER, A.; BRAGANÇA, M.; LE DIVIDICH, J. Influence of high ambient temperature on performance of reproductive sows. Livest. Prod. Sci., v.52, p.123-133, 1997.

QUINIOU, N.; NOBLET, J. Influence of high ambient temperatures on performance of multiparous lactating sows. J. Anim. Sci., v.77, p.2124-2134, 1999.

QUIÑONERO, J.; GARCÍA-SANTAMARÍA, C.; MARÍA-DOLORES, E. et al. Physiological indicators of stress in gestating sows under different cooling systems. Pesqui. Agropecu. Bras., v.44, n.11, p.1549-1552, 2009.

RENAUDEAU, D.; COLLIN, A.; YAHAV, S. et al. Adaptation to hot climate and strategies to alleviate heat stress in livestock production. Animal, v.6, p.707-728. 2012.
STORTI, A.A.; NASCIMENTO, M.R.B.M.; ANTUNES, R.C. et al. Níveis de hormônios tireoideanos circulantes, desempenho e qualidade de carcaça e carne de suínos em crescimento e terminação. Ciênc. Rural, v.43, p.139-144, 2012.

STOKOL, T.; ERB, N. A comparison of platelet parameters in EDTA and Citrate anticoagulated blood in dogs. Vet. Clin. Pathol, v.36, p-148154, 2007.

THOM, E.C. The discomfort index. Weatherwise, v.12, p.57-60, 1959.

TOLON, Y.B; NÃ̃̃S, I.A. Avaliação de tipos de ventilação em maternidade de suínos. Eng. Agríc., v.25, p.565-574, 2005.

WEGNER, K.; LAMBERTZ, C.; DAS, G. et al. Effects of temperature and temperature-humidity index on the reproductive performance of sows during summer months under a temperate climate. Anim. Sci. J., v.87, p.1334-1339, 2016.

WILLIANS, A.M.; SAFRANSKI, T.J.; SPIERS, D.E. et al. Effects of a controlled heat stress during late gestation, lactation, and after weaning on thermoregulation, metabolism, and reproduction of primiparous sows. J. Anim. Sci., v.91, p.2700-2714, 2013. 